\title{
A Bibliometric Investigation of Flipped Classroom Research during 2000-2015
}

\author{
https://doi.org/10.3991/ijet.v12i06.7095 \\ Lie Yang \\ Wuhan University of Technology, Wuhan, China \\ yanglie612@whut.edu.cn \\ Tiantian Sun \\ Wuhan University of Technology, Wuhan, China \\ stt313352667@163.com \\ Yanli Liu \\ Wuhan University of Technology, Wuhan, China \\ liuyanli_1@163.com
}

\begin{abstract}
The paper analyzed the global growth and development of flipped classroom research productivity in terms of publication output as reflected in SCI/SSCI for the period 2000-2015. Publication types and languages, characteristics of articles outputs, countries, subject categories and journals, and the frequency of keywords were analyzed using bibliometric methods. There are 149 articles in 78 journals listed in $41 \mathrm{SCI} / \mathrm{SSCI}$ subject categories. A sharp growth trend of publication output was observed during 2011-2015. USA played a predominant role in flipped classroom research. Education educational research, chemistry and medical were the top 3 categories and "active learning" and "blended learning" recent major topics of flipped classroom research during the past 16 years. The results could help researchers understand the characteristics of research output and search hot spots of flipped education field.
\end{abstract}

Keywords - flipped classroom; active learning; blended learning; bibliometric

\section{Introduction}

There has been a growing interest in using the flipped classroom in both K-12 education and higher education [1]. In the flipped classroom, what is traditionally done in class and as homework are switched or flipped [2]. It was reported that flipped classroom was successful for both faculty and students [2]. There have been a number of published papers which have reported the investigation and application of flipped classroom. Some of them reviewed the trends of flipped classroom development. Tomory and Watson [3] explains how issues regarding dual credit and Advanced Placement high school science courses could be mitigated via a flipped classroom instructional model. Leung et al. [4] gave a short review on flipped 
classroom approach and O'Flaherty and Phillips [5] reviewed the applications of flipped classrooms in higher education.

Despite the importance of flipped classroom, there have been few attempts to gather data about the worldwide scientific production of flipped classrooms research. Bibliometric studies provided an accurate and presumably objective method to measure the contribution of a paper to the advancement of knowledge [6, 7]. Bibliometric indicators including publication countries, research fields, journals, and author keywords have been frequently used to analyze the trends and performance [811]. The objective of this study is to analyze the status and trends of flipped classroom research in the last 16 years in order to help researchers understand the panorama of global flipped classroom research.

\section{Methods}

The data used in this study were based on the database of the SCI and SSCI published by Thomson Reuters Web of Science, Philadelphia, PA, USA. "Flipped classroom" and "inverted classroom" were used as the string to search titles, abstracts, and keywords from 2000 to 2015 . The records were then downloaded to a compact disc. Care has been exercised to examine the data collected to assure their identity. Subsequently, the data were analyzed by Microsoft Excel. Articles from Hong Kong, Macao, and Taiwan were not included in Mainland China. The investigation was conducted to analyze the research trends and performance that including characteristics of article output, publication outputs of countries and institutions, distribution of outputs in subject categories and journals, and frequency of author keywords, from 2000 to 2015. HistCite software developed by Garfield and colleagues [12] was used to figure out the total global citation score (TGCs).

\section{Results and Discussion}

\subsection{Document types, publication output}

There were 149 papers related to flipped classroom research in the database, including 6 document types. Articles (101) comprised $67.78 \%$ of the total production, followed distantly by meeting abstracts $(28 ; 18.79 \%)$, editorial materials $(13 ; 8.72 \%)$, news item $(3,2.01 \%)$, reviews $(2 ; 1.34 \%)$ and letter $(2 ; 1.34 \%)$. English was the most frequently used language, making up $97.32 \%$ of all the published articles. The publications devoted to flipped classroom research from 2000 to 2015 are illustrated in Fig. 1. Although flipped teaching was firstly proposed in 2000, few studies were indexed in SCI/SSCI database. Actually a sharp growth trend of publication output was observed until 2011. The yearly number of articles increased notably from 1 in 2011 to 83 in 2015. 


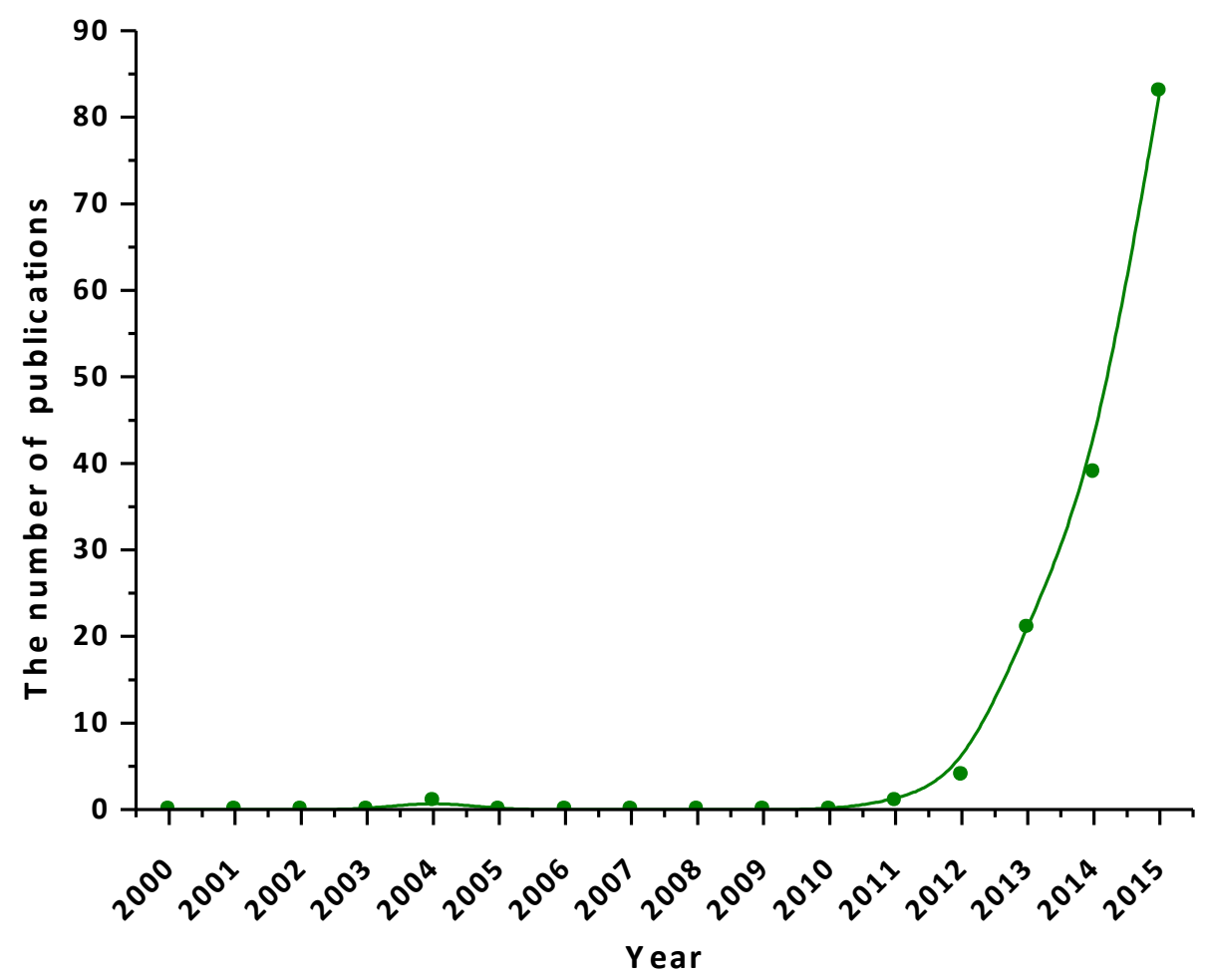

Fig. 1. The number of articles on flipped classroom during 2000-2015

\subsection{Publication distribution of countries and institutes}

149 articles were published by authors from 25 countries/territories. The most productive countries/territories are listed in Table 1. Two North and Central American countries, three European countries, four Asian countries/territories, and Australia were ranked in the top 10 . The domination role in publication of USA was obviously found from Table 1, taking a share of $68.456 \%$. Actually, USA acts as the origin country of flipped classroom, which firstly introduced by Lage MJ and Platt G [13]. A large amount studies focusing on flipped classroom were conducted by various American scholars $[4,5]$. In addition, various related conferences were held in USA. The Spring 2014 ConfChem conference, Flipped Classroom, was held from May 9 to June 12, 2014, and contained 8 papers and a poster session discussing a variety of ways to engage students within a flipped learning approach to the classroom [14]. By contrast, other countries/territories published fewer research articles during the study period.

Besides, the 10 most productive institutions are presented in Table 2. It can be seen from the table that 9 of top 10 institutions were from USA and only one was from PR China. Univ N Carolina has published 5 publications ranked first, as the leading 
institution in both of article quantity and TGCS. The results showed a good agreement with countries/territories. USA played a predominant role in flipped classroom research. It may be attributed to the vigorous development of flipped classroom in United States.

Table 1. The 10 most productive countries/territories of articles during 2000-2015.

\begin{tabular}{lcc}
\hline \multicolumn{1}{c}{ Countries/Territories } & Records & \% of 149 \\
\hline USA & 102 & 68.456 \\
Australia & 9 & 6.04 \\
Canada & 8 & 5.369 \\
Mainland China & 6 & 4.027 \\
Taiwan & 3 & 2.013 \\
Spain & 3 & 2.013 \\
Turkey & 2 & 1.342 \\
Singapore & 2 & 1.342 \\
Saudi Arabia & 2 & 1.342 \\
Germany & 2 & 1.342 \\
\hline
\end{tabular}

Table 2. The 10 most productive institutions of articles during 2000-2015.

\begin{tabular}{lcccc}
\hline \multicolumn{1}{c}{ Institutions } & Country & Records & TGCs* & \% of 149 \\
\hline Univ N Carolina & USA & 5 & 103 & 3.356 \\
Univ Georgia & USA & 4 & 26 & 2.685 \\
Yale Univ & USA & 3 & 76 & 2.013 \\
Univ Florida & USA & 3 & 0 & 2.013 \\
Purdue Univ & USA & 3 & 8 & 2.013 \\
Hong Kong Inst Educ & PR China & 3 & 10 & 2.013 \\
Ctr Coll Danville & USA & 3 & 4 & 2.013 \\
Cleveland Clin & USA & 3 & 36 & 2.013 \\
Univ Washington & USA & 2 & 23 & 1.342 \\
Univ Rochester & USA & 2 & 16 & 1.342 \\
\hline
\end{tabular}

*TGCs total global citation score.

\subsection{Publication patterns: source titles and subject categories}

The 149 articles were published in a wide range of 78 journals. The 10 journals with the greatest number of published papers are listed in Table 3. Journal of Chemical Education, Abstracts of Papers of The American Chemical Society, FASEB Journal, Computers Education, American Journal of Pharmaceutical Education, and Academic Medicine published most articles in the 16 years. The top 10 journals published 61 articles, sharing $40.94 \%$ of the total amount. The observations indicated that flipped classroom applications on chemistry, medical and computer were paid more attentions.

There was a great diversity including 41 subject categories related to the research topic of flipped classroom in Journal Citation Reports (JCR) of the ISI. Top 10 
subject categories with the most articles are listed in Table 4, containing the rank and the percentage of the paper quantities. The five most common categories were education educational research $(54.362 \%)$, chemistry $(14.094 \%)$, health care sciences services $(10.067 \%)$, nursing $(8.054 \%)$ and pharmacology pharmacy $(6.711 \%)$ along 16 years. The domination role of education educational research could be explained by increasing studies on educational methods and theories. Benefits and strategies [15], podcasts and video application [16] were studied during the teaching and learning investigation. Long et al. [1] conducted their study to address the instructor's perspective, and instructors' perspectives on technology integration can directly influence their practice of incorporating technology in instruction. Hao and Lee [17] attempted to figure out pre-service teacher concerns about teaching in technologyintegrated flipped classrooms. In addition, a study was conducted to determine the effects of a flipped classroom (i.e., reversal of time allotment for lecture and homework) and innovative learning activities on academic success and the satisfaction of nursing students [18]. Except for education educational research, chemistry and medical (contained health care sciences services, nursing and pharmacology pharmacy) also attracted great attention. A large amount of articles focused on both of chemistry and medical teaching. A flipped classroom format was implemented and evaluated by Weaver and Sturtevant in the chemistry majors' sequence at Purdue University over a period of three years to look at quantitative measures of student performance in the flipped versus the traditional lecture approach of this chemistry course [19]. Seery [20] analyzed student engagement with flipped chemistry lectures and aim to build up a profile of how the flipped lecture works for middle stage undergraduate students. Similarly, flipped method has been widely applied on medical courses. Liebert et al. [21] attempted to apply flipped classroom to the surgery core clerkship and observed high learner satisfaction, effective knowledge acquisition, and increased career interest in surgery. A randomised control trial was conducted to evaluate the flipped classroom pedagogy for a freshman year nutritional science module [22]. In addition, flipped classroom has attracted great interest on nursing education [23-26]. Overall, education educational research, chemistry and medical were the top 3 categories in flipped classroom during the past 16 years.

Table 3. The 10 most productive journals during 2000-2015.

\begin{tabular}{lccc}
\hline \multicolumn{1}{c}{ Journals } & IF(2015) & Records & \% of 149 \\
\hline Journal of Chemical Education & 1.225 & 13 & 8.725 \\
Abstracts of Papers of The American Chemical Society & -- & 8 & 5.369 \\
FASEB Journal & 5.299 & 6 & 4.027 \\
Computers Education & -- & 6 & 4.027 \\
American Journal of Pharmaceutical Education & 1.196 & 6 & 4.027 \\
Academic Medicine & 3.857 & 6 & 4.027 \\
Nurse Educator & 0.991 & 4 & 2.685 \\
Medical Teacher & 2.355 & 4 & 2.685 \\
Medical Education & 3.369 & 4 & 2.685 \\
BMC Medical Education & 1.312 & 4 & 2.685 \\
\hline
\end{tabular}


Table 4. The 10 most productive subject categories during 2000-2015.

\begin{tabular}{lcc}
\hline \multicolumn{1}{c}{ Subject categories } & Records & \% of 149 \\
\hline Education educational research & 81 & 54.362 \\
Chemistry & 21 & 14.094 \\
Health care sciences services & 15 & 10.067 \\
Nursing & 12 & 8.054 \\
Pharmacology pharmacy & 10 & 6.711 \\
Engineering & 9 & 6.04 \\
Computer science & 7 & 4.698 \\
Biochemistry molecular biology & 7 & 4.698 \\
Life sciences biomedicine other topics & 6 & 4.027 \\
Cell biology & 6 & 4.027 \\
\hline
\end{tabular}

\subsection{Research emphasis: author keywords}

As author keyword analysis provides effective information about research trends for researchers, it has proved to be important for monitoring the development of research topics [27]. According to the statistics, 247 author keywords were used from 2000 to 2015 . The top 10 most active author keywords in the 16 years are listed in Table 5. Except for the searching word "flipped classroom" and "inverted classroom", the two most frequently used keywords were "active learning" and "blended learning". Great efforts have been focused on "active learning" and "blended learning". Roach[28] studied new methods to increase interaction and active learning in economics and found that an instructional design that is beneficial across student groups. Kakosimos [29] attempted to develop a methodology to improve the effectiveness of flipped classroom, adaptive e-learning, and active learning. Gilboy [2] studied how to enhance student engagement using the flipped classroom within 2 undergraduate nutrition courses. Moreover, "internet/web-based learning" and "computer-based learning" acted as significant research topics in flipped classroom research. For example, blog was applied in a chemical course and proved beneficial for active learning [30].

Table 5. The 10 most active author keywords during 2000-2015.

\begin{tabular}{lcc}
\hline \multicolumn{1}{c}{ Author keywords } & Records & Share (\%) \\
\hline flipped classroom & 38 & $9.20 \%$ \\
active learning & 18 & $4.36 \%$ \\
blended learning & 12 & $2.91 \%$ \\
first-year undergraduate/general & 10 & $2.42 \%$ \\
student-centered learning & 8 & $1.94 \%$ \\
education & 8 & $1.94 \%$ \\
inverted classroom & 7 & $1.69 \%$ \\
second-year undergraduate & 6 & $1.45 \%$ \\
internet/web-based learning & 6 & $1.45 \%$ \\
computer-based learning & 5 & $1.21 \%$ \\
\hline
\end{tabular}




\section{Conclusions}

In this study, some significant points have been obtained on the research trends throughout the period from 2000 to 2015. The number of articles about flipped classroom increased slowly during 2000-2010, but showed a shape growth in 20112015. In total, there are 149 articles in 78 journals listed in $41 \mathrm{SCI} / \mathrm{SSCI}$ subject categories. The research on the fields of flipped classroom focused on education educational research, chemistry and medical. According the analysis of author keywords, the two most frequently used keywords were "active learning" and "blended learning". The findings of this study can help relevant researchers understand the performance of flipped classroom research in the world, and suggest directions for further research.

\section{Acknowledgement}

This work was supported by Program of National Natural Science Foundation of China (No. 51508430).

\section{References}

[1] Long, T., Cummins, J., Waugh, M. (2016) Use of the flipped classroom instructional model in higher education: instructors' perspectives. Journal of Computing in Higher Education, https://doi.org/10.1007/s12528-016-9119-8

[2] Gilboy, M.B., Heinerichs, S., Pazzaglia, G. (2015) Enhancing Student Engagement Using the Flipped Classroom. Journal of Nutrition Education and Behavior, 47:109-114. https://doi.org/10.1016/j.jneb.2014.08.008

[3] Tomory, A., Watson, S.L. (2015) Flipped classrooms for advanced science courses. Journal of Science Education and Technology, 24:875-887. https://doi.org/10.1007/s10956 $\underline{-015-9570-8}$

[4] Leung, J.Y.C., Kumta, S.M., Jin, Y., Yung, A.L.K. (2014) Short review of the flipped classroom approach. Medical Education, 48:1127-1127. https://doi.org/10.1111/medu.12 $\underline{576}$

[5] O'Flaherty, J., Phillips, C. (2015) The use of flipped classrooms in higher education: A scoping review. Internet and Higher Education, 25:85-95. https://doi.org/10.1016/j.iheduc. 2015.02.002

[6] Huang, Y., Zhao, X. (2008) Trends of DDT research during the period of 1991 to 2005. Scientometrics, 75:111-122. https://doi.org/10.1007/s11192-007-1828-3

[7] Yang, L., Chen, Z., Liu, T., Gong, Z., Yu, Y., Wang, J. (2013) Global trends of solid waste research from 1997 to 2011 by using bibliometric analysis. Scientometrics,96:133-146. https://doi.org/10.1007/s11192-012-0911-6

[8] Chen, H., Ho, YS. (2015) Highly cited articles in biomass research: A bibliometric analysis. Renewable and Sustainable Energy Reviews, 49:12-20. https://doi.org/10.1016/ j.rser.2015.04.060

[9] CHIU, W.T., HO, Y.S. (2007) Bibliometric analysis of tsunami research. Scientometrics,73:3-17. https://doi.org/10.1007/s11192-005-1523-1 
[10] Chuang, K.Y., Huang, Y.L., Ho, Y.S. (2007) A bibliometric and citation analysis of stroke-related research in Taiwan. Scientometrics,72:201-212. https://doi.org/10.1007/s11 192-007-1721-0

[11] Dong, B., Xu, G., Luo, X., Cai, Y., Gao, W. (2012) A bibliometric analysis of solar power research from 1991 to 2010. Scientometrics, 93:1101-1117. https://doi.org/10.1007/s11 192-012-0730-9

[12] Garfield, E. (2004) Historiographic mapping of knowledge domains literature. Journal of Information Science, 30:119-145. https://doi.org/10.1177/0165551504042802

[13] Lage, M.J., Platt, G. (2000) The internet and the inverted classroom. Journal of Economic Education, 31:11. https://doi.org/10.1080/00220480009596756

[14] Luker, C., Muzyka, J., Belford, R. (2015) Introduction to the Spring 2014 ConfChem on the Flipped Classroom. Journal of Chemical Education,92:1564-1565. https://doi.org/10.1021/acs.jchemed.5b00024

[15] McDonald, K., Smith, C.M. (2013) The Flipped Classroom for Professional Development: Part I. Benefits and Strategies. Journal of Continuing Education in Nursing, 44:437-438. https://doi.org/10.3928/00220124-20130925-19

[16] Smith, C.M., McDonald, K. (2013) The Flipped Classroom for Professional Development: Part II. Making Podcasts and Videos. Journal of Continuing Education in Nursing,44:486487. https://doi.org/10.3928/00220124-20131025-93

[17] Hao, Y., Lee, K.S. (2016) Teaching in flipped classrooms: Exploring pre-service teachers'concerns. Computers in Human Behavior, 57:250-260. https://doi.org/10.1016/ j.chb.2015.12.022

[18] Missildine, K., Fountain, R., Summers, L., Gosselin, K. (2013) Flipping the Classroom to Improve Student Performance and Satisfaction. Journal of Nursing Education, 52:597-599. https://doi.org/10.3928/01484834-20130919-03

[19] Weaver, G.C., Sturtevant, H.G. Design, implementation, and evaluation of a flipped format general chemistry course. Journal of Chemical Education,92:1437-1448. https://doi.org/10.1021/acs.jchemed.5b00316

[20] Seery, M.K. (2015) Confchem conference on flipped classroom: Student engagement with flipped chemistry lectures. Journal of Chemical Education, 92:1566-1567. https://doi.org/10.1021/ed500919u

[21] Liebert, C.A., Lin, D.T., Mazer, L.M., Bereknyei, S., Lau, J.N. (2016) Effectiveness of the Surgery Core Clerkship Flipped Classroom: a prospective cohort trial. The American Journal of Surgery, 211:451-457. https://doi.org/10.1016/j.amjsurg.2015.10.004

[22] Chan, S.M., Tse, J.Y., Yu, P.H. (2015)The flipped classroom in an undergraduate nutritional science course: A pilot study. SpringerPlus, 4:3. https://doi.org/10.1186/21931801-4-S2-P3

[23] Betihavas, V., Bridgman, H., Kornhaber, R., Cross, M. (2016) The evidence for 'flipping out': A systematic review of the flipped classroom in nursing education. Nurse Education Today, 38:15-21. https://doi.org/10.1016/j.nedt.2015.12.010

[24] Schlairet, M.C., Green, R., Benton, M.J. (2014) The Flipped Classroom Strategies for an Undergraduate Nursing Course. Nurse Educator, 39:321-325. https://doi.org/10.1097/ NNE.0000000000000096

[25] McGowan, B.S., Balmer, J.T., Chappell, K. (2014) Flipping the Classroom: A Data-Driven Model for Nursing Education. Journal of Continuing Education In Nursing, 45:477-478. https://doi.org/10.3928/00220124-20141027-11

[26] Critz, C.M., Knight, D. (2013) Using the Flipped Classroom in Graduate Nursing Education. Nurse Educator, 38:210-213. https://doi.org/10.1097/NNE.0b013e3182a0e56a 
[27] Wen, H., Huang, Y. (2012) Trends and performance of oxidative stress research from 1991 to 2010. Scientometrics, 91:51-63. https://doi.org/10.1007/s11192-011-0535-2

[28] Roach, T. (2014) Student perceptions toward flipped learning: New methods to increase interaction and active learning in economics. International Review of Economics Education, 17:74-84. https://doi.org/10.1016/j.iree.2014.08.003

[29] Kakosimos, K.E. (2015) Example of a micro-adaptive instruction methodology for the improvement of flipped-classrooms and adaptive-learning based on advanced blendedlearning tools. Education for Chemical Engineers,12:1-11. https://doi.org/10.1016/j.ece. 2015.06.001

[30] Haile, J.D. (2015) Confchem conference on flipped classroom: Using a blog to flip a classroom. Journal of Chemical Education, 92:1572-1573. https://doi.org/10.1021/ed5009 $17 \mathrm{j}$

\section{$7 \quad$ Authors}

Lie Yang is a teacher at School of Resources and Environmental Engineering, Wuhan University of Technology, Wuhan, China.

Tiantian Sun is with School of Resources and Environmental Engineering, Wuhan University of Technology, Wuhan, China.

Yanli Liu is with School of Resources and Environmental Engineering, Wuhan University of Technology, Wuhan, China.

Article submitted 01 May 2017. Published as resubmitted by the authors 13 June 2017. 